\title{
Patterns of use and perceived value of social media for population health among population health stakeholders: a cross- sectional web-based survey
}

\author{
Sungwon Yoon ${ }^{1,2}$, Sharon Wee ${ }^{1}$ Vivian S. Y. Lee ${ }^{1}$, Jing Lin ${ }^{1}$ and Julian Thumboo ${ }^{1,2,3^{*}}$
}

\begin{abstract}
Background: Although existing studies have described patterns of social media use in healthcare, most are focused on health professionals in one discipline. Population health requires a multi-disciplinary approach to ensure diversity and to include diverse stakeholders. To date, what is known about using social media in population health is focused on its potential as a communication tool. This study aims to investigate patterns of use and perceived value of social media usage among stakeholders in population health practice, policy, or research.

Methods: We conducted a web-based survey of delegates attending the Singapore Population Health Conversations and Workshop. We designed a 24-item questionnaire to assess 1) social media use in terms of type of platform and frequency of use; 2) perceptions of social media relevance and impact on population health; and 3) top three areas in population health that would benefit from social media. We used descriptive and logistic regression analyses to assess the relationships between variables.

Results: Of the 308 survey respondents, 97.7\% reported that they use social media in some form. Messaging (96.8\%) was the most dominant activity when using social media. Challenges in implementing social media for population health were time investment by health care professionals (56.2\%) and patient adoption (52.9\%). The top three population health areas that would benefit most from using social media were the promotion of healthy behaviors (60.7\%), community engagement (47.7\%), and preventive care (40.6\%). Older respondents ( $>=40$ years) were less likely to view social media as useful for the promotion of healthy behaviors ( $\mathrm{OR}=0.34 ; 95 \% \mathrm{Cl}: 0.19-0.60)$. Non-social/healthcare professionals were more likely to consider social media to be useful for community engagement $(\mathrm{OR}=1.74 ; 95 \% \mathrm{Cl}: 1.10-2.76)$. For preventive care, older respondents $(\mathrm{OR}=0.51 ; 95 \% \mathrm{Cl}: 0.32-0.82)$ and non-social/healthcare professionals were less likely to view social media as useful (OR $=0.61 ; 95 \% \mathrm{Cl}$ : 0.38-0.97).

Conclusions: Our findings suggest that it may be important to select the specific care areas that would benefit most from using social media. The time investment needed by population health professionals should be fully addressed in planning to maximize the application and potential value of social media.
\end{abstract}

\footnotetext{
* Correspondence: julian.thumboo@singhealth.com.sg

'Regional Health System, Singapore Health Services, Singapore, Singapore

${ }^{2}$ Programme in Health Services and Systems Research, Duke-NUS Medical School, Singapore, Singapore

Full list of author information is available at the end of the article
}

(c) The Author(s). 2021 Open Access This article is licensed under a Creative Commons Attribution 4.0 International License, which permits use, sharing, adaptation, distribution and reproduction in any medium or format, as long as you give appropriate credit to the original author(s) and the source, provide a link to the Creative Commons licence, and indicate if changes were made. The images or other third party material in this article are included in the article's Creative Commons licence, unless indicated otherwise in a credit line to the material. If material is not included in the article's Creative Commons licence and your intended use is not permitted by statutory regulation or exceeds the permitted use, you will need to obtain permission directly from the copyright holder. To view a copy of this licence, visit http://creativecommons.org/licenses/by/4.0/ The Creative Commons Public Domain Dedication waiver (http://creativecommons.org/publicdomain/zero/1.0/) applies to the data made available in this article, unless otherwise stated in a credit line to the data. 
Keywords: Social media, Population health, Cross-sectional survey, Healthcare professionals, Social care professionals

\section{Background}

The growth of social media has changed the way we communicate. The number of social media users worldwide was estimated to be 3.6 billion in 2020 [1, 2]. In many parts of the world, social media is becoming an integral part of our lives. In Singapore, more than 4.6 million people were active social media users as of 2020 , representing $79 \%$ of the total population $[3,4]$. In public health and medicine, social media has been defined as the collective of online communication channels that allow for real-time and on-the-go communication [5]. Social media platforms include wikis (e.g., Wikipedia), messaging (e.g., WhatsApp and Telegram), social networking sites (e.g., Facebook, LinkedIn), media-sharing sites (e.g., YouTube, Instagram, Snapchat), blogs and micro-blogs (e.g., Blogger, Twitter) and immersive worlds (e.g., Second Life) [5, 6].

In healthcare settings, social media has become an increasingly popular tool for communication and information sharing [7]. This trend is demonstrated by the number of systematic reviews published over the past decade: from 2004 to 2009 , two systematic reviews were conducted on the topic of social media and health whereas from 2014 to 2016, the number of systematic reviews increased to thirty-four [5]. There are two main reasons why social media tools have been employed in healthcare. The first reason is to improve reach and engagement of patients and the public [8]. To this end, various health departments and agencies have used social media tools to disseminate health information (e.g. in medical emergencies [9] and mass media educational campaigns [10]) and/ or to support chronic disease self-management programs [11]. Leading healthcare organizations such as the US Centers for Disease Control and Prevention $[12,13]$, National Health Service in the United Kingdom [14], and Kaiser Permanente [15] have maintained a significant social media presence, and have actively encouraged social media usage by providing toolkits for their employees to generate content [16, 17]. Interventions tapping on social media for patients with particular health concerns (e.g. Human Immunodeficiency Virus, arthritis) have also been wellreceived [11, 18].

The second reason why social media tools have been employed in healthcare is for communication among healthcare professionals, e.g. to facilitate exchange of information and for professional networking $[8,19]$. Traditionally, professional networking and information sharing have taken place at scientific meetings and conferences. However, social media offers a new avenue for communication for professional development [20-22] and has proven especially useful during the COVID-19 pandemic $[23,24]$. Indeed, one study reported that 53 and $35 \%$ of healthcare professionals used social media to exchange medical knowledge and enhance their productivity respectively [19]. Dieleman and Duncan [25] described how healthcare professionals utilized an online discussion group to exchange professional advice, establish direct personal contacts among group members, and share materials such as updated policies and protocols. A recent integrative review also found that healthcare professionals used social media to develop virtual communities that facilitated knowledge sharing and evidence-informed practice [26]. Importantly, the review identified a key limitation in the current literature: most published studies have largely focused on professionals in a single homogeneous discipline for a discrete clinical specialty.

Population health is defined as the "health outcomes of a group of individuals" and the larger community [27]. Population health also extends beyond the provision of traditional medical care to encompass social, environmental, economic, and cultural factors which influence health. The nature of population health necessitates a multidisciplinary approach to ensure diversity and to include health and social care professionals $[28,29]$. Social media can be a useful avenue to integrate health and social care services [30-32]. An integrative review of social media use by health and social care professionals demonstrated the potential of virtual communication via social media for inter-professional collaboration, but highlighted that active participation from members was required [33]. To date, what is known about using social media in population health is focused on its potential as a communication tool. Little is known about the utility and acceptability of the use of social media for various population health areas as perceived by the stakeholders in population health [34, 35]. Therefore, this study aimed to investigate patterns of use and perceived value of social media usage for population health among stakeholders in population health practice, policy, or research in Singapore.

Singapore is an urban city-state in Southeast Asia, with a rapidly aging population. The proportion of residents aged 65 years and over has increased from $8.7 \%$ in 2008 to $14.4 \%$ in 2019 [36], and this figure is expected to double to $27 \%$ by 2030 . Singapore's national healthcare 
expenditure has correspondingly increased from $\$ 13$ billion in 2012 to $\$ 22$ billion in 2017, or about $11 \%$ per annum [37]. To address the challenges of an aging population, the Ministry of Health developed and is implementing a strategic plan for population health which includes community care transformation to better integrate social and healthcare services [38, 39]. Previously, health and social care services were managed separately, with at times suboptimal collaboration among health and social care professionals [40]. Despite care integration efforts, a recent study suggests that there remains a lack of interprofessional communication among health and social care professionals beyond their organizational and professional boundaries [41]. The present paper represents an attempt to gain a better understanding of the receptivity of social media as a potential platform for improving communication and quality community care as perceived by health and social care professionals in population health.

\section{Methods}

\section{Study design}

We designed and conducted a cross-sectional survey using survey software (i.e., SurveyMonkey). The survey was completed anonymously to encourage honest and unbiased responses. Respondents were delegates at the Singapore Population Health Conversations and Workshop, an annual nation-wide networking event for practitioners of population health in Singapore that is aimed at sharing experiences and discussing new initiatives in the emerging field of population health [42]. The delegates registered for the workshop with an email address, through which we invited them to participate in the survey by selecting the survey link to participate (www. surveymonkey.com/r/3YDVDHG). Following internationally accepted ethical codes, respondents were duly informed of the purpose of the survey and were reminded of their participation rights before proceeding to take the survey. This study was approved by SingHealth Institutional Review Board (CIRB ref. 2019/ 2240). We closed the survey link after the workshop ended.

\section{Questionnaire development}

The questionnaire was developed and adapted based on a review of relevant literature [7, 31, 43-46]. It was pretested among ten health and social care professionals and modified according to their feedback. The 24-item questionnaire (Additional File 1) comprised two sections. The first section consisted of questions designed to gather information on respondents' social media usage in terms of type of platform and frequency of use (daily; weekly; monthly; infrequently/none), social media usage in their organization (yes/no) and perceptions of the relevance and impact of social media on population health (i.e. benefits and limitations of social media for population health work, target population health areas, target age group and target recipients most likely to benefit from using social media). The second section collected information on the respondents' characteristics such as age, sex, and primary role in population health. The survey was conducted in English (which was the language used for the host event) and required approximately 15 min to complete.

\section{Classification of variables}

The type of social media platform was categorized into 4 functional groups: messaging (WhatsApp and Telegram), networking (Facebook and LinkedIn), media sharing (YouTube, Instagram, and Snapchat), and microblogging (Twitter) $[6,47]$. The frequency of social media usage by type of social media platform was dichotomized into frequent use (daily, weekly, monthly) and infrequent use (infrequently/none). Organizational use of social media was dichotomized into yes (selected area(s) in which organization used social media) and no (none selected). Level of understanding of population health was categorized into 4 groups based on a rating of 1 to 10: 1-4 (not at all/ a little); 5-6 (moderately good); 7-8 (good); and 9-10 (very good).

\section{Statistical analysis}

Descriptive summary statistics were presented as counts and percentages. Responses from the following questions were used for model building:

- What are the top three areas in which social media would be useful for population health?

- Do you use social media for population health work?

- Which social media platform do you use and how frequently do you use it?

- In which area(s) does your organization currently use social media for population health?

- Please rate your level of understanding pertaining to population health.

The top three areas in which social media would be useful for population health were the dependent variables. We analyzed factors predicting targeted population health areas that would benefit from using social media using logistic regression analysis.

The baseline models first estimated each of the top three population health areas reported useful by respondents after adjusting for demographic characteristics (i.e., age, sex), and primary role in population health. Subsequently, we added personal use/non-use of social media, frequency of social media usage by type of social media platform, organizational use/non-use of social 
media for population health work, and level of understanding of population health.

To improve model fit, we performed a stepwise backward elimination procedure, with a $p$-value more than or equal to 0.1 as the significance level for variable removal. At every step, age, sex, and primary role were kept in the model. We specified the odds ratios, 95\% confidence intervals (95\% CI), $p$-values, and goodnessof-fit statistics in Additional File 2, and presented significant variables of the final model in the results section. All statistical analyses were conducted using STATA version 15 . A $p$-value of less than .05 was considered statistically significant.

\section{Results}

We sent an invitation email and one reminder to all workshop registrants $(n=917)$. Of 412 respondents, 308 completed the survey, yielding a response rate of $33.6 \%$. Only completed surveys were included in the analysis. Characteristics of the respondents are shown in Table 1. Of the respondents, $48.7 \%$ were below the age of 40 years and $77.6 \%$ were female. Less than half $(44.5 \%)$ of the respondents were health and social care

Table 1 Characteristics of respondents

\begin{tabular}{|c|c|c|}
\hline \multirow[b]{2}{*}{ Age } & \multicolumn{2}{|c|}{$\begin{array}{l}\text { Overall (\%) } \\
(N=308)\end{array}$} \\
\hline & & \\
\hline below 40 & 150 & $(48.70)$ \\
\hline 40 and above & 158 & $(51.30)$ \\
\hline \multicolumn{3}{|l|}{ Sex } \\
\hline Male & 69 & $(22.40)$ \\
\hline Female & 239 & $(77.60)$ \\
\hline \multicolumn{3}{|l|}{ Primary Role } \\
\hline Healthcare professionals and social care professionals & 137 & $(44.48)$ \\
\hline Others (program managers, researchers, administrators) & 169 & $(54.87)$ \\
\hline \multicolumn{3}{|l|}{ Use of Social Media } \\
\hline Yes & 301 & $(97.73)$ \\
\hline No & 7 & $(2.27)$ \\
\hline \multicolumn{3}{|l|}{ Use of Social Media for Population Health work } \\
\hline Yes & 69 & $(22.40)$ \\
\hline No & 239 & $(77.60)$ \\
\hline \multicolumn{3}{|l|}{ Organisational use of Social Media for Population Health } \\
\hline Yes & 238 & $(77.27)$ \\
\hline No & 70 & $(22.73)$ \\
\hline \multicolumn{3}{|l|}{ Level of Understanding of Population Health } \\
\hline Not at all/A little & 69 & $(22.40)$ \\
\hline Moderately good & 125 & $(40.58)$ \\
\hline Good & 98 & $(31.82)$ \\
\hline Very good & 16 & $(5.19)$ \\
\hline
\end{tabular}

professionals while the remaining respondents were non-care professionals (e.g., program managers, administrators, researchers, and students). While the vast majority of respondents $(97.7 \%)$ reported that they used social media in some form, only $22.4 \%$ reported that they had used social media for population health work. However, $77.3 \%$ reported that their organizations used social media for population health. More than two-thirds of the respondents indicated that their level of understanding of population health was good or moderately good (72.4\%).

Figure 1 shows the frequency of social media use by type of social media platform. Messaging (i.e., WhatsApp and Telegram) was the most dominant activity when using social media, with $96.1 \%$ of respondents using it daily, followed by networking (i.e., Facebook and LinkedIn; $61.4 \%$ used these daily). Media sharing (i.e., YouTube, Instagram, and Snapchat) and microblogging (i.e., Twitter) were the two least frequently used social media platforms (32.5 and 3.9\% used these daily respectively).

Perceptions of the utility of social media for population health are presented in Table 2. Respondents were asked to choose three areas in population health that would benefit most from using social media. The top three areas identified were the promotion of healthy behaviors (60.7\%), community engagement (47.7\%), and preventive care $(40.6 \%)$. The most commonly reported target age group was 30-39 years (92.2\%) followed by 40-49 years (89.6\%). Overall, respondents' (87.3\%) views were that caregivers would benefit most from using social media as a communication tool for population health followed by healthcare professionals in the community (84.1\%). Approximately three quarters agreed that social media sites or apps $(77.0 \%)$ and face-to-face group sessions $(73.1 \%)$ were two useful modes of communication for population health work. The least useful mode of communication for population health work was telephone calls $(27.3 \%)$ followed by text messages (33.1\%). The main challenges in implementing social media for population health were time investment by health care professionals $(56.2 \%)$ and patient adoption (53.0\%).

Table 3 presents the associations between respondent characteristics and the top three population health areas reported useful by respondents. Older respondents were less likely to view social media as useful for the promotion of healthy behaviors (OR $=0.34$; 95\% CI: 0.19-0.60; $P<.001)$. Non-health/social care professionals were more likely to consider social media as useful for community engagement $(\mathrm{OR}=1.74 ; \quad 95 \% \quad \mathrm{CI}: \quad 1.10-2.76$; $P<.05)$. Lastly, older respondents and non-health/social care professionals were less likely to consider social media to be useful for preventive care $(\mathrm{OR}=0.51 ; 95 \%$ CI: $0.32-0.82 ; P<.05 ; \quad O R=0.61 ; 95 \%$ CI: $0.38-0.97$; 


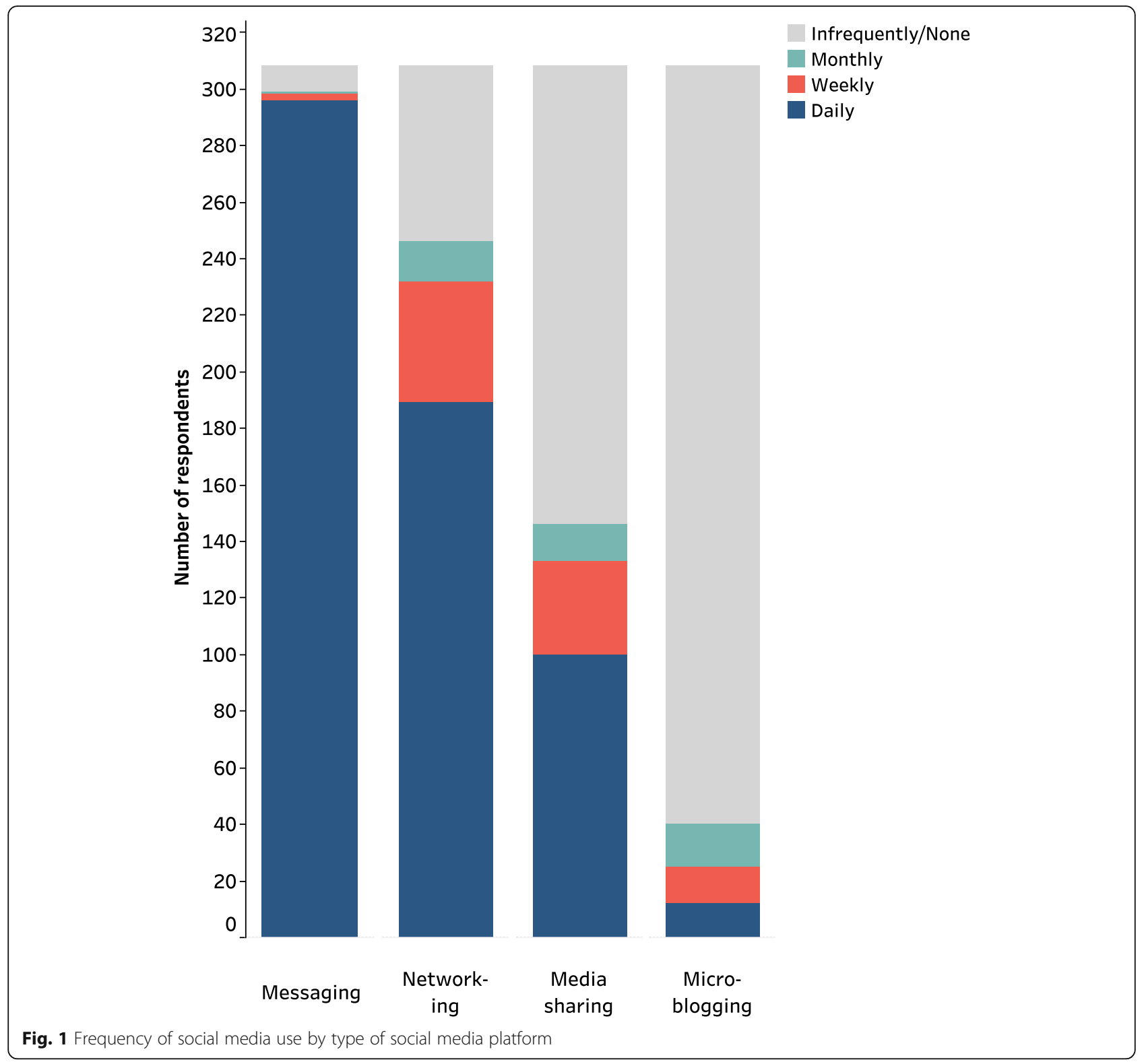

$P<.05)$ while female respondents were more likely to view social media as useful $(\mathrm{OR}=1.81 ; 95 \% \mathrm{CI}$ : $1.01-$ 3.24; $P<.05)$.

\section{Discussion}

This study investigated the patterns of social media use and perceived value of social media for population health among health, social care and other professionals working in population health. To the best of our knowledge, this is the first study to examine specific areas in which population health would benefit from using social media, from the perspective of population health stakeholders.

The vast majority of respondents were regular social media users, which is similar to prior studies [48, 49].
Social media was used predominantly for messaging, followed by networking and media sharing. Microblogging was the least frequently used social media platform. This finding indicates that social media may have a potential to provide a medium for communication and networking for professionals in population health. This finding is in line with other studies that found healthcare professionals often used a communication application, such as WhatsApp or Facebook [19]. Research shows that interaction and communication with a diverse range of professionals beyond an individual organization or a single specialty enabled healthcare workers to make more informed decisions and to develop work-related resources [26]. Future implementation should consider how existing social media platforms for communication 
Table 2 Perceptions of social media use for population health

\begin{tabular}{lccc}
\hline & $\mathbf{n}$ & $\mathbf{( \% )}^{\mathbf{a}}$ \\
\hline Population health areas that would benefit from social & media use \\
Promotion of health behaviors & 187 & $(60.71)$ \\
Community engagement & 147 & $(47.73)$ \\
Preventive care (e.g. diabetes screening, immunization) & 125 & $(40.58)$ \\
Chronic disease management & 119 & $(38.64)$ \\
Care coordination & 78 & $(25.32)$ \\
Mental health & 55 & $(17.86)$ \\
Social support & 54 & $(17.53)$ \\
Health-social interface & 56 & $(18.18)$ \\
Population health policy & 34 & $(11.04)$ \\
Intermediate to long term care & 22 & $(7.14)$ \\
Palliative/End-of-life care & 18 & $(5.84)$ \\
Research & 10 & $(3.25)$ \\
Acute disease management & 9 & $(2.92)$ \\
Post-acute care recovery & 8 & $(2.60)$
\end{tabular}

Age groups (years) that would benefit from social media use

12 and below

13-19

20-29

30-39

40-49

$50-59$

60-69

70 and above

Recipients that would benefit from social media use Caregivers

Healthcare professionals in the community

Patients

Healthcare professionals in acute hospitals

Social care professionals in acute hospitals

Useful modes of communication in population health

Social media sites/apps

Face-to-face group sessions

Websites

Text messages

Telephone calls

Main challenges for the use of social media

Time investment by health care professionals

Patient adoption

Infrastructure development of technological approaches

Providing supervision and follow-up

Adoption by health care professionals

Cost investment

${ }^{a}$ Total number does not add up to 308 because multiple selections were allowed and networking could be usefully integrated into the development of shared spaces for population health professionals to interact.

We found that most respondents viewed social media as a useful mode of communication for population health, particularly for caregivers. This perspective is supported by studies showing that online support delivered via social media decreased the burden of care for informal caregivers and increased the contact time clinicians had with patients and their caregivers [50]. A scoping review of 284 articles also found that the use of social media improved self-care and clinical decisionmaking for patients and their caregivers [51]. Similarly, caregivers reported decreased burden, reduced stress, and increased support following a 6-week intervention using online peer support groups [52]. Despite these positive outcomes, a study in Singapore showed that an online forum was not well received by caregivers of patients with advanced cancer, citing reasons such as not being computer savvy, rarely surfing the internet and not feeling comfortable sharing information with strangers on an online platform [53]. These findings, together with the finding from our study, indicate that digital literacy, issues of trust and privacy, and sufficient resources are needed for successful caregiver adoption of social media.

Our study found social media to be of most value for the following three areas in population health: i) promotion of healthy behaviors, ii) community engagement, and iii) preventive care. The younger respondents were, the more likely they were to view social media as useful for the promotion of healthy behaviors and preventive care. Younger respondents would have grown up with digital technology and would therefore be more familiar with social media campaigns promoting healthy behaviors and encouraging preventive care. In contrast, older respondents may not be active users of social media, and hence were less likely to come across population health campaigns through social media platforms. The overall positive perceptions of social media in younger age groups is similar to the findings of other studies that younger health care workers [49] and doctors [48] were more likely to support the use of social media for healthcare-related tasks than their older counterparts.

While health and social care professionals viewed social media as useful for preventive care, they did not view it to be useful for community engagement. This finding could be explained by the nature of population health work. Health and social care professionals are directly involved in the care of the population and therefore they are cognizant of the effort required for community engagement. Community engagement involves empowering the local community with skills to take ownership and make decisions that improve the health and 
Table 3 Association between participant characteristics and target population health areas

\begin{tabular}{|c|c|c|c|c|c|c|c|c|c|}
\hline & \multicolumn{3}{|c|}{$\begin{array}{l}\text { Promotion of healthy } \\
\text { behaviors }\end{array}$} & \multicolumn{3}{|c|}{$\begin{array}{l}\text { Community } \\
\text { Engagement }\end{array}$} & \multicolumn{3}{|c|}{ Preventive Care } \\
\hline & OR & {$[95 \% \mathrm{Cl}]$} & $p$-value & OR & {$[95 \% \mathrm{Cl}]$} & $p$-value & OR & {$[95 \% \mathrm{Cl}]$} & $p$-value \\
\hline \multicolumn{10}{|l|}{ Age } \\
\hline below 40 & Ref & & & Ref & & & Ref & & \\
\hline 40 and above & 0.34 & {$[0.19-0.60]$} & $<0.001$ & 1.24 & {$[0.78-1.95]$} & 0.36 & 0.51 & {$[0.32-0.82]$} & $<0.05$ \\
\hline \multicolumn{10}{|l|}{ Sex } \\
\hline Male & Ref & & & $\operatorname{Ref}$ & & & Ref & & \\
\hline Female & 0.85 & {$[0.48-1.51]$} & 0.58 & 0.81 & {$[0.46-1.40]$} & 0.45 & 1.81 & {$[1.01-3.24]$} & $<0.05$ \\
\hline \multicolumn{10}{|l|}{ Primary role } \\
\hline Health and social care professionals & Ref & & & Ref & & & Ref & & \\
\hline Others (program managers, researchers, administrators) & 1.15 & {$[0.72-1.84]$} & 0.57 & 1.74 & {$[1.10-2.76]$} & $<0.05$ & 0.61 & {$[0.38-0.97]$} & $<0.05$ \\
\hline
\end{tabular}

wellbeing of residents [54]. This entails fostering collaboration and trust through relationship building with community members $[41,55,56]$. As relationships are built through in-person interactions which involve faceto-face contact, health and social care professionals responses might reflect the view that social media may not replace in-person communication when building and establishing relationships in the local community [56]. This also echoes our survey finding that face-to-face sessions were perceived to be the second most useful mode of communication (followed by social media sites and applications).

Overall, our findings show that when implementing social media for population and community care initiatives, it may be important to select the specific care areas that would benefit most from using social media. For example, health promotion messages and campaigns can be usefully integrated into social media platforms to influence the behaviors of intended audiences; however face-to-face contact might be selected for activities that require and / or aim to build professional-patient relationships. In addition, it may be important to take into account the age of population health professionals when implementing population health interventions that harness social media. Lastly, notwithstanding the perceived benefits of social media for population health, it is not without drawbacks. The time investment needed by population health professionals and patient adoption should be addressed when developing social media programs for population health [57-59].

While focusing on population health areas in which social media might be beneficial, attention could also be given to counter misleading health information disseminated through social media that may have deleterious effects on population health. A recent systematic review observed an increased prevalence of misinformation on social media primarily related to vaccines and infectious diseases [60]. The negative public health effects of misinformation through social media have been especially pertinent in light of the ongoing COVID-19 pandemic and vaccine hesitancy [61]. Future research should examine how best to combat the negative effects of health-related misinformation on social media.

The strength of this study included the participation of population health practitioners from multiple disciplines, which provided broad perspectives of the utility of social media from different stakeholders. Our findings should also be interpreted in light of the following limitations: the survey was based on opportunistic sampling and participation was voluntary. First, the relatively low response rate (33.6\%) might have resulted in potential biases limiting generalizability of our findings. Second, in our study, only $2.3 \%$ of respondents reported that they did not use social media. This is relatively low compared to surveys conducted elsewhere [62] and may reflect selection bias, where only those familiar with social media chose to respond to the survey. Third, this study is cross-sectional and therefore causal inferences cannot be drawn. Lastly, our study did not include some important population health stakeholders, in particular patients and community members. Future studies should examine the perceptions of these stakeholders on the value of social media for population health.

\section{Conclusions}

This study provides valuable insights into the views of population health stakeholders on the value of social media for population health work, and can inform the design of population health programs and interventions that harness social media platforms. Optimizing population health and community care requires a greater attention to enhancing person-centered care and healthsocial interface. While social media can be a useful tool for population health, understanding target audiences, 
specific care areas, and needs would improve its optimal adoption and utilization.

\section{Abbreviations}

CDC: Centers for Disease Control and Prevention; NHS: National Health Service; Cl: Confidence interval; OR: Odds ratio

\section{Supplementary Information}

The online version contains supplementary material available at https://doi. org/10.1186/s12889-021-11370-y.

Additional file 1: Word format of the questionnaire that was uploaded online.

Additional file 2: Supplementary Tables showing the logistic regression models used for the stepwise backward elimination procedure.

\section{Acknowledgments}

The authors would like to thank all respondents who took part in the study. The authors are also grateful to Bernie YJ Lee and Zoey HX Lim for excellent administrative support in the design, development, and implementation of the online survey.

\section{Authors' contributions}

SY, JL, and JT conceptualized the study. SY and SW designed the questionnaire and drafted the manuscript. VL performed the analysis and interpretation of data. All authors read and approved the final manuscript.

\section{Funding}

This work was supported by the National Medical Research Council (NMRC) through the SingHealth PULSES centre grant NMRC/CG/027/2017. The funding body had no role in the study design, collection, analysis, interpretation of data and manuscript writing.

\section{Availability of data and materials}

The dataset used and analyzed during the current study is available from the corresponding author on reasonable request.

\section{Declarations}

\section{Ethics approval and consent to participate}

As the online survey was completed anonymously, consent to participate was implied when the respondent submitted the survey. The need for ethics approval for this study was waived by the SingHealth Centralised Institutional Review Board (CIRB ref. 2019/2240).

\section{Consent for publication}

Not applicable.

\section{Competing interests}

The authors declare that they have no competing interests.

\section{Author details}

${ }^{1}$ Regional Health System, Singapore Health Services, Singapore, Singapore. ${ }^{2}$ Programme in Health Services and Systems Research, Duke-NUS Medical School, Singapore, Singapore. ${ }^{3}$ Department of Rheumatology and Immunology, Singapore General Hospital, Singapore, Singapore.

Received: 13 September 2020 Accepted: 24 June 2021

Published online: 05 July 2021

\section{References}

1. Tankovska H. Number of global social network users 2017-2025. https:// www.statista.com/statistics/278414/number-of-worldwide-social-networkusers/. Accessed 18 Feb 2021

2. Chen J. 36 Essential social media marketing statistics to know for 202 (cited 3 Feb 2021). https://sproutsocial.com/insights/social-media-statistics/. Accessed $1 \mathrm{Jul} 2021$

3. Kemp S. Digital 2020: Global Digital Overview. https:/wearesocial.com/ digital-2020. Accessed 1 Sep 2020.
4. Shahari F. $10+$ Interesting Social Media Statistics in Singapore (Updated 3 Jan 2021). https://cloudrock.asia/sg/blog/social-media-statistics-singapore/. Accessed 1 Jul 2021

5. Giustini DM, Ali SM, Fraser M, Boulos MNK. Effective uses of social media in public health and medicine: a systematic review of systematic reviews. Online J Public Health Inform. 2018;10(2):e215. https://doi.org/10.5210/ojphi. v10i2.8270.

6. Grajales FJ, Sheps S, Ho K, Novak-Lauscher H, Eysenbach G. Social media: a review and tutorial of applications in medicine and health care. J Med Internet Res. 2014;16(2):e13. https://doi.org/10.2196/jmir.2912.

7. Smailhodzic E, Hooijsma W, Boonstra A, Langley DJ. Social media use in healthcare: a systematic review of effects on patients and on their relationship with healthcare professionals. BMC Health Serv Res. 2016:16(1): 442. https://doi.org/10.1186/s12913-016-1691-0.

8. Moorhead SA, Hazlett DE, Harrison L, Carroll JK, Irwin A, Hoving C. A new dimension of health care: systematic review of the uses, benefits, and limitations of social media for health communication. J Med Internet Res. 2013;15(4):e85. https://doi.org/10.2196/jmir.1933.

9. Wolkin AF, Schnall AH, Nakata NK, Ellis EM. Getting the message out: social media and word-of-mouth as effective communication methods during emergencies. Prehosp Disaster Med. 2019:34(1):89-94. https://doi.org/10.101 7/S1049023X1800119X

10. Mahadir Naidu B, Mohd Yusoff MF, Abdullah S, Musa KI, Yaacob NM Mohamad MS, et al. Factors associated with the severity of hypertension among Malaysian adults. PLoS One. 2019;14(1):e0207472. https://doi.org/1 $0.1371 /$ journal.pone.0207472

11. De Angelis G, Brosseau L, Davies B, King J, Wells GA. The use of information and communication technologies by arthritis health professionals to disseminate a self-management program to patients: a pilot randomized controlled trial protocol. Digit Health. 2018:4:205520761881957. https://doi. org/10.1177/2055207618819571.

12. Centers for Disease Control \& Prevention. CDC Facebook. https://www.fa cebook.com/CDC. Accessed 2 Aug 2019.

13. Centers for Disease Control \& Prevention. CDC's official Twitter source for daily credible health \& safety updates from Centers for Disease Control \& Prevention. https://twitter.com/cdcgov. Accessed 2 Aug 2019.

14. NHS. nhs.uk Facebook: Home. https://www.facebook.com/NHSwebsite/. Accessed 2 Aug 2019

15. Kaiser Permanente. Media Contacts. https://about.kaiserpermanente.org/ who-we-are/contact-us/media-contacts. Accessed 13 Aug 2019.

16. A social media toolkit for the NHS. 2016. https://www.nhsemployers.org/-/ media/Employers/Publications/Social-media/Social-Media-Toolkit.pdf. Accessed 13 Aug 2019.

17. Centers for Disease Control and Prevention. The Health Communicator's Social Media Toolkit. 2011. https://www.cdc.gov/socialmedia/tools/ guidelines/pdf/socialmediatoolkit_bm.pdf. Accessed 13 Aug 2019.

18. Dulli L, Ridgeway K, Packer C, Plourde KF, Mumuni T, Idaboh T, et al. An online support group intervention for adolescents living with HIV in Nigeria: a pre-post test study. JMIR Public Health Surveill. 2018:4(4):e12397. https:// doi.org/10.2196/12397

19. Hazzam J, Lahrech A. Health care professionals' social media behavior and the underlying factors of social media adoption and use: quantitative study. J Med Internet Res. 2018;20(11):e12035. https://doi.org/10.2196/12035.

20. Shaw T, McGregor D, Brunner M, Keep M, Janssen A, Barnet S. What is eHealth (6)? development of a conceptual model for ehealth: qualitative study with key informants. J Med Internet Res. 2017;19:e324. https://doi. org/10.2196/jmir.8106

21. McNab C. What social media offers to health professionals and citizens. Bull World Health Organ. 2009:87(8):566. https://doi.org/10.2471/BLT.09.066712.

22. Haruta J, Tsugawa S, Ogura K. Exploring the structure of social media application-based information-sharing clinical networks in a community in Japan using a social network analysis approach. Family Med Community Health. 2020;8(4):e000396. https://doi.org/10.1136/fmch-2020-000396.

23. Cheng $P$, Xia G, Pang P, Wu B, Jiang W, Li YT, et al. COVID-19 epidemic peer support and crisis intervention via social media. Community Ment Health J. 2020:56(5):786-92. https://doi.org/10.1007/s10597-020-00624-5.

24. Cree-Green M, Carreau AM, Davis SM, Frohnert BI, Kaar JL, Ma NS, et al. Peer mentoring for professional and personal growth in academic medicine. J Investig Med. 2020;68(6):1128-34. https://doi.org/10.1136/jim-2020-001391.

25. Dieleman C, Duncan EAS. Investigating the purpose of an online discussion group for health professionals: a case example from forensic occupational 
therapy. BMC Health Serv Res. 2013;13(1):253. https://doi.org/10.1186/14726963-13-253.

26. Rolls $\mathrm{K}$, Hansen M, Jackson D, Elliott D. How health care professionals use social media to create virtual communities: an integrative review. J Med Internet Res. 2016;18:e166. https://doi.org/10.2196/jmir.5312.

27. Kindig D, Stoddart G. What is population health? Am J Public Health. 2003; 93(3):380-3. https://doi.org/10.2105/AJPH.93.3.380.

28. Brewster AL, Brault MA, Tan AX, Curry LA, Bradley EH. Patterns of collaboration among health care and social services providers in communities with lower health care utilization and costs. Health Serv Res. 2018;53:2892-909. https://doi.org/10.1111/1475-6773.12775.

29. Newman M, Bangpan M, Kalra N, Mays N, Kwan I, Roberts T. Commissioning in health, education and social care: models, research bibliography and indepth review of joint commissioning between health and social care agencies. Report. In: Research Evidence in Education Library. London: EPPICentre, Social Science Research Unit, Institute of Education, University of London. 2012. https://eppi.ioe.ac.uk/cms/Portals/0/PDF\%20reviews\%20a nd\%20summaries/Commissioning\%202012Newman.pdf?ver=2012-09-1 7-123424-943. Accessed 2 Aug 2019.

30. Hudnut-Beumler J, Po'e E, Barkin S. The use of social Media for Health Promotion in Hispanic populations: a scoping systematic review. JMIR Public Health Surveill. 2016;2(2):e32. https://doi.org/10.2196/publichealth. 5579 .

31. Stead M, Angus K, Langley T, Katikireddi SV, Hinds K, Hilton S, et al. Mass media to communicate public health messages in six health topic areas: a systematic review and other reviews of the evidence. Public Health Research. 2019;7(8):1-206. https://doi.org/10.3310/phr07080.

32. Soto MV, Balls-Berry JE, Bishop SG, Aase LA, Timimi FK, Montori VM, et al. Use of web 2.0 social media platforms to promote community-engaged research dialogs: a preliminary program evaluation. JMIR Res Protoc. 2016;5: e183. https://doi.org/10.2196/resprot.4808.

33. Mcloughlin C, Patel KD, O'callaghan T, Reeves $\mathrm{S}$. The use of virtual communities of practice to improve interprofessional collaboration and education: findings from an integrated review the use of virtual communities of practice to improve interprofessional collaboration and education: findings from an i. J Interprof Care. 2017;32:136-42.

34. Avery E, Lariscy R, Amador E, Ickowitz T, Primm C, Taylor A. Diffusion of social media among public relations practitioners in health departments across various community population sizes. J Public Relat Res. 2010;22(3): 336-58. https://doi.org/10.1080/10627261003614427.

35. Safi S, Thiessen T, Schmailz KJG. Acceptance and resistance of new digital technologies in medicine: qualitative study. JMIR Res Protoc. 2018;7(12): e11072. https://doi.org/10.2196/11072.

36. Department of Statistics, Singapore. Population and Population Structure. https://www.singstat.gov.sg/find-data/search-by-theme/population/popula tion-and-population-structure/latest-data. Accessed 6 Sep 2020

37. Ministry of Health. Speech by Mr Gan Kim Yong, Minister for Health, at the Ministry of Health Committee of Supply Debate 2020. 2020; March. https:// www.moh.gov.sg/news-highlights/details/speech-by-mr-gan-kim-yongminister-for-health-at-the-ministry-of-health-committee-of-supply-debate-2 020-on-thursday-5-march-2020. Accessed 1 Jul 2021.

38. Poon $\mathrm{CH}$. Public healthcare sector to be reorganised into 3 integrated clusters, new polyclinic group to be formed. The Straits Times 2017. https:// www.straitstimes.com/singapore/health/public-healthcare-sector-to-bereorganised-into-3-integrated-clusters-new. Accessed 2 Aug 2019.

39. Ministry of Health. Speech by Minister for Health, Mr Gan Kim Yong, at the MOH Committee of Supply Debate 2019. 2019; Mar. https://www.moh.gov. sg/news-highlights/details/peech-by-mr-gan-kim-yong-minister-for-health-a t-the-ministry-of-health-committee-of-supply-debate-2019. Accessed 13 Aug 2019.

40. Choo C. Govt to expand, consolidate social and health-related services for seniors under Ministry of Health. In: Today: Singapore. 19 Feb 2018. https:// www.todayonline.com/singapore/govt-expand-consolidate-social-and-hea Ith-related-services-seniors-under-ministry-health. Accessed 1 Jul 2021.

41. Thumboo J, Yoon S, Wee S, Yeam CT, Low ECT, Lee CE. Developing population health research priorities in Asian city state: results from a multistep participatory community engagement. PLoS One. 2019;14(5):e0216303. https://doi.org/10.1371/journal.pone.0216303.

42. Singapore Population Health Conversation \& Workshop. 2019. https://www. singhealth.com.sg/rhs/about-us/Pages/events.aspx. Accessed 13 Aug 2019.
43. Lu Y, Wu Y, Liu J, Li J, Pengzhu Z. Understanding health care social media use from different stakeholder perspectives: a content analysis of an online health community. J Med Internet Res. 2017;19:e109. https://doi.org/10.21 96/jmir.7087.

44. Elaheebocus SMRA, Weal M, Morrison L, Yardley L. Peer-based social media features in behavior change interventions: systematic review. J Med Internet Res. 2018;20(2):e20. https://doi.org/10.2196/jmir.8342.

45. Gilmour J, Machin T, Brownlow C, Jeffries C. Facebook-based social support and health: a systematic review. Psychol Popul Media. 2019;9:328-46.

46. Volpp KG, Mohta NS. Social Networks to Improve Patient Health Advisor Analysis. NEJM Catalyst. 2017; November.

47. Wikipedia. Social Media. https://en.wikipedia.org/wiki/Social_media. Accessed 1 Jul 2021.

48. Brown J, Ryan C, Harris A. How doctors view and use social media: a National Survey. J Med Internet Res. 2014;16(12):e267. https://doi.org/10.21 96/jmir.3589.

49. Surani Z, Hirani R, Elias A, Quisenberry L, Varon J, Surani S, et al. Social media usage among health care providers. BMC Res Notes. 2017;10(1):654 https://doi.org/10.1186/s13104-017-2993-y.

50. Watkins T. Decreasing informal caregiver burden with social media. Home Healthc Nurse. 2014;32(5):304-8.

51. Hamm MP, Chisholm A, Shulhan J, Milne A, Scott SD, Given LM, et al. Social media use among patients and caregivers: a scoping review. BMJ Open. 2013;3(5):e002819. https://doi.org/10.1136/bmjopen-2013-002819.

52. Wilkerson DA, Brady E, Yi E-H, Bateman DR. Friendsourcing peer support for Alzheimer's caregivers using Facebook social media. J Technol Hum Serv. 2018;36(2-3):105-24. https://doi.org/10.1080/15228835.2018.1449709.

53. Leow MQH, Chan SWC. Evaluation of a video, telephone follow-ups, and an online forum as components of a psychoeducational intervention for caregivers of persons with advanced cancer. Palliat Support Care. 2016;14(5): 474-8. https://doi.org/10.1017/S1478951516000225.

54. National Institute for Health and Care Excellence. Community engagement: improving health and wellbeing and reducing health inequalities (NG44). NICE guideline. 2016. https://www.nice.org.uk/guidance/ng44. Accessed 1 Jul 2021.

55. Charles A, Ham C, Baird B, Alderwick H, Bennett L. Reimagining community services: making the most of our assets. In: The King's Fund: Publications. 2018. https://www.kingsfund.org.uk/publications/community-services-assets. Accessed 1 Jul 2021.

56. Tomayko EJ, Prince RJ, Cronin KA, Parker T, Kim K, Grant VM, et al. Healthy children, strong families 2 : a randomized controlled trial of a healthy lifestyle intervention for American Indian families designed using community-based approaches. Clin Trials. 2017;14:152-61.

57. Wright CJC, Schwarzman J, Dietze PM, Crockett B, Lim MSC. Barriers and opportunities in the translation of mobile phone and social media interventions between research and health promotion practice in Australia: a qualitative study of expert perspectives. Health Res Policy Syst. 2019;17(1): 5. https://doi.org/10.1186/s12961-018-0406-x.

58. Thackeray R, Neiger BL, Smith AK, Van Wagenen SB. Adoption and use of social media among public health departments. BMC Public Health. 2012; 12(1):242. https://doi.org/10.1186/1471-2458-12-242.

59. Woldaregay AZ, Issom D-Z, Henriksen A, Marttila H, Mikalsen M, Pfuhl G, et al. Motivational factors for user engagement with mHealth apps. Studi Health Technol Inform. 2018;249:151-7.

60. Wang Y, McKee M, Torbica A, Stuckler D. Systematic literature review on the spread of health-related misinformation on social media. Soc Sci Med. 2019; 240:112552. https://doi.org/10.1016/j.socscimed.2019.112552.

61. Tasnim S, Hossain M, Mazumder H. Impact of rumors and misinformation on COVID-19 in social media. J Prev Med Public Health. 2020;53(3):171-4. https://doi.org/10.3961/jpmph.20.094.

62. Loeb S, Bayne CE, Frey C, Davies BJ, Averch TD, Woo HH, et al. Use of social media in urology: data from the American urological association (AUA). BJU Int. 2014;113(6):993-8. https://doi.org/10.1111/bju.12586.

\section{Publisher's Note}

Springer Nature remains neutral with regard to jurisdictional claims in published maps and institutional affiliations. 